\title{
Carbon sequestration: how much can forestry sequester $\mathrm{CO} 2$ ?
}

\begin{abstract}
This mini paper reviewed key principles of carbon sequestration in the concept and quest to understand that land and forests have been accounted huge potential source of storing and referred as natural scrubbers or natures "carbon sinks". Generally, in scientific term, one way of reducing the emissions of carbon dioxide into the atmosphere is to store carbon or $\mathrm{CO} 2$ in any medium other than the atmosphere. This paper outlines the main definition and estimates of amount of $\mathrm{CO}$ sequestered annually by plants while determining the total (green) weight of the tree, determine the weight of carbon in the tree and the weight of carbon dioxide sequestered in the tree. Prominent evaluation examples involve maple-beech-birch forests and white and red pine forests (25 and 120 years) while reflecting to world agro forestry sequestration calculation. Furthermore, the paper discusses the key process of trees as collectors of $\mathrm{CO} 2$ : chemistry of the action. The mini review concludes the assertion and supported by UN Framework Convention on Climate Change (UNFCC) and the global order of Clean Development Mechanisms (CDM).
\end{abstract}

Keywords: carbon sequestration, forestry, carbon dioxide, carbon sinks, UNFCC and CDM
Volume 2 Issue 3 - 2018

\author{
Egbuche Christian Toochi \\ Department of Forestry and Wildlife Technology, Federal \\ University of Technology Owerri, Nigeria
}

Correspondence: Egbuche Christian Toochi, Department of Forestry and Wildlife Technology, Federal University of Technology Owerri, Imo State, Nigeria, Email ctoochi@yahoo.co.uk

Received: March 03, 2018| Published: May 31, 2018

\section{Introduction}

Sequestration in its concept is very complex which has been applicable to rates though vary greatly in consideration of age, composition, location of any forests and soil type. This provoking presentation seeks to question and recapture the view of how much $\mathrm{CO}_{2}$ does a tree take up? The emergence of climate change and global warming has been identified by scientist and occur frequently. This phenomenon is been triggered by anthropogenic (human) activities thereby the discharge of large amounts of greenhouse gases into the atmosphere. In a general scientific term, one way of reducing the emissions of carbon dioxide into the atmosphere is to store carbon or $\mathrm{CO}_{2}$ in any medium other than the atmosphere. The biological and geological mediums are two major and vast different ways of carbon sequestration. Land and forests have been accounted huge potential source of storing and referred as natural scrubbers or natures "carbon sinks". The process of photosynthesis permits green plants to uptake $\mathrm{CO}_{2}$ from the atmosphere and convert it into organic carbon as they grow and in turn organic carbon is converted back to $\mathrm{CO}_{2}$ when it is eaten or decomposed known as the process of respiration. This is to say, activities that increase photosynthesis and/or decreases respiration is regarded of great advantage in the global carbon reduction. Terrestrial and mostly trees (plants) store the most carbon because of large volume storage and long-lived storage. Various parts of plants as trunks, leaves, wood, roots as well as the soil in which the plants are fixed as do not decompose or burn, stores carbon from the atmosphere. Plants of all categories as well as non tilled fields and grasslands are carbon sinks and storage and thereby store organic carbon in the soil. On global rating, soil carbon sequestration could offset as much as 15 percent of fossil fuel emissions. This mini review paper hereby supports activities that have carbon sinking benefits such as improved soil quality, increased crop yields, and some wildlife habitat conservation approaches.

\section{Problem significant}

The critical concern on the role of soil and forests in the global carbon budget and effects of carbon sequestration has been incorporated in international treaties. In Article 3.4 of the Kyoto protocol, soil and forests has been identified as a potential sink of carbon which various nations tends to establish greenhouse gas inventories and carbon management authorities. This review paper is significant in understanding the potential for forests to sequester carbon as a major terrestrial sequestration agent. The main factors of $\mathrm{C}$ disturbance include forest management, fires, floods, deforestation, reforestation, agricultural practices and drainage.

\section{Theoretical methods}

Key definitions of carbon sequestration were presented. Theories in calculation from plant growth stages and maple-beech-birch forests and white and red pine forests ( 25 and 120 years) while reflecting to world agro forestry sequestration calculation.

\section{Estimates of amount of $\mathrm{CO}$ sequestered annually by plants}

Tropical climates support greatly the sequestration of atmospheric carbon dioxide and documented at an average of 50 pounds of carbon dioxide per tree per year. It is provoking that not much research and investigation has been conducted on plant species especially in the tropical forests. Generally, the rate of carbon sequestration depends on plant growth characteristics of individual tree species, the density of the tree's wood, and the conditions for growth where the tree is planted and plant stage-that is to say the greatest sequestration stage is in the younger stages of tree growth, between 20 to 50 years. ${ }^{1} \mathrm{~A}$ rough calculation and estimate the amount of $\mathrm{CO}_{2}$ sequestered in a given tree. 


\section{Definition}

$\mathrm{T}_{(\mathrm{CO} 2)} / \mathrm{t}_{\text {age }},=\mathrm{A}_{\text {rate }}$

$\mathrm{T}_{(\mathrm{CO} 2)-}$ estimated amount of $\mathrm{CO}_{2}$ sequestered in a given tree

$/ t_{\text {age }}$-divide by the age of the particular tree

$\mathrm{A}_{\text {rate }}$-annual sequestration rate.

In considering the various mechanisms of understanding carbon sequestration in plant species, some basic student learning process identified in determining carbon sequestration capacity in any given tree species ${ }^{2}$ as in Figure 1.

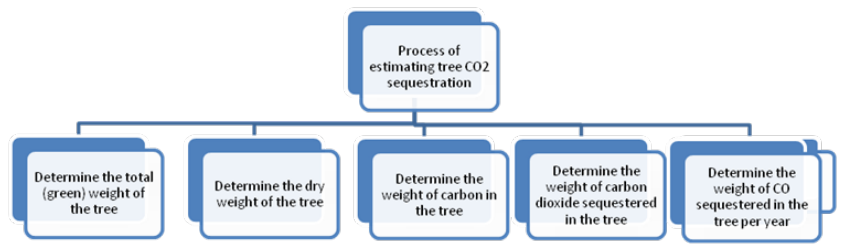

Figure 1 The various mechanisms of understanding carbon sequestration in plant species, some basic student learning process identified in determining carbon sequestration capacity.

\section{Determine the total (green) weight of the tree}

Depending on the tree species, ${ }^{2}$ a simple algorithm can be applied to weigh any tree species as below

$\mathrm{W}=$ Above-ground weight of the tree in pounds

$\mathrm{D}=$ Diameter of the trunk in inches

$\mathrm{H}=$ Height of the tree in feet

\section{Determine the weight of carbon in the tree}

The average carbon content is generally $50 \%$ of the tree's total volume. ${ }^{3}$ Therefore, in determining the weight of carbon in the tree, multiply the dry weight of the tree by $50 \%$.

\section{Determine the weight of carbon dioxide sequestered in the tree}

Chemical composition of $\mathrm{CO}_{2}$ means and that composed of one molecule of Carbon and 2 molecules of Oxygen. The atomic weight of Carbon is 12.001115. The atomic weight of Oxygen is 15.9994. In line with the documentaries of ${ }^{4,5}$ the weight of $\mathrm{CO}_{2}$ in trees is determined by the ratio of $\mathrm{CO}_{2}$ is $\mathrm{C}+2 * \mathrm{O}=43.999915$ to $\mathrm{C}_{\text {is }}$ $43.999915 / 12.001115=3.6663$ therefore, to determine the weight of carbon dioxide sequestered in the tree, multiply the weight of carbon in the tree by 3.6663 .

\section{Northeast, maple-beech-birch forests}

a) 25 year old forest: $12,000 \mathrm{lbs}$ of carbon $/ 25=480 \mathrm{lbs}$ of C per acre per year x $44 / 12=1,7601$ bs of $\mathrm{CO}_{2}$ per acre per year

b) $\mathbf{1 2 0}$ year old forest: $128,000 \mathrm{lbs}$ of carbon/120 =1,066 lbs of C per year per acre $\mathrm{x} 44 / 12=3,909 \mathrm{lbs}$ of $\mathrm{CO}_{2}$ per acre per year

c) 25 year old forest: 1,760lbs of $\mathrm{CO} 2$ per acre per year/700 trees $=$ average of $2.52 \mathrm{lbs}$ of $\mathrm{CO} 2$ per tree per year (rounded to 3 lbs) d) 120 year old forest: 3,909lbs of $\mathrm{CO} 2$ per year per acre = average of 5.581bs of $\mathrm{CO}_{2}$ per tree per year

\section{Northeast, white and red pine forests}

i. 25 year old forest: $67,000 \mathrm{lbs}$ of carbon $/ 25=2,680 \mathrm{lbs}$ of $\mathrm{C}$ per acre per year x 44/12 $=9,826 \mathrm{lbs}$ of $\mathrm{CO}_{2}$ per acre per year $/ 700$ $=$ average of $14 \mathrm{lbs}$ of $\mathrm{CO}_{2}$ per year per tree (rounded to $15 \mathrm{lbs}$ )

ii. 120 year old forest: $246,000 \mathrm{lbs}$ of carbon/120 $=2,050 \mathrm{lbs}$ of C per acre per year x $44 / 12=7,516 \mathrm{lbs}$ of $\mathrm{CO}_{2}$ per acre per year $/$ $700=$ average of $11.7 \mathrm{lbs}$ of $\mathrm{CO}_{2}$ per year per tree.

Source: Forests and Global Change, ${ }^{6}$ world Agroforestry Centre's "Agroforestry Database" and how much a Calliandra calothyrsus might sequester in a year. This is based on an extension publication from the University of Nebraska. ${ }^{7}$

Note: Tree density varies, and an average is always taken in trees per acre (from DOE's "Sector-Specific Issues and Reporting Methodologies Supporting the General Guidelines for the Voluntary Reporting of Greenhouse Gases under Sections 1605(b) of the Energy Policy Act of 1992")

\section{Discussion}

\section{The process of trees as collectors of $\mathrm{CO} 2$ : chemistry of the action}

All green plants, trees assimilate $\mathrm{CO}_{2}$ from the atmosphere through the process of photosynthesis. The simple sugar molecules that are initially formed from $\mathrm{CO}_{2}$ are then combined to produce cellulose, as well as lignin in the case of woody plant organs. Much of the carbon that is assimilated through photosynthesis is released again as $\mathrm{CO}_{2}$ through respiration-the energy costs associated with growth maintenance of living material. The remaining carbon is allocated to leaf, root, seed, and wood and branch biomass. At an annual timescale, the carbon associated with short-lived components of woodland is returned to the atmosphere through decomposition, with only a proportion of fixed carbon being retained in the longer term as wood. The process of photosynthesis converts two chemicals; carbon dioxide and water into simple carbohydrates, using sunlight as the energy source. The process takes place within the leaf and other green surfaces of plants. However, only part of the radiant energy from the sun is used in this way. At best, a plant can convert only about $6 \%$ of the total incoming radiation into stored energy. Water enters the plant mainly through the roots and brings with it essential nutrients. Carbon dioxide enters as a gas, mainly through holes (stomata) on plant leaves. Stomata open in response to light, but close in the dark and in response to adverse conditions such as lack of water or high temperature. When a crop is growing vigorously and other constraints, a daily inflow, via the stomata, of over $150 \mathrm{~kg} / \mathrm{ha}$ carbon dioxide is needed. The amount contained in the air above the crop to a height of over 20 meters. Water is lost from plants while the stomata are open, sometimes over 100t/ha each day.

\section{Conclusion}

It is noted that Kyoto protocol 1979 stated the need for terrestrial ecosystems especially growing trees to sequester carbon. Different vegetation and plant species, soils and forest management regimes influences the potential of trees in their capacity to sequester carbon. The increasing climate change scenario and warmer climatic condition as well as human anthropogenic activities have positioned climate and global change ecology as an agenda. This assertion was supported 
by UN Framework Convention on Climate Change (UNFCC) and the global order of Clean Development Mechanisms (CDM). Furthermore, this presentation is response to the provoking demand for basic knowledge for carbon sequestration in the context of how much forestry has contributed in $\mathrm{CO}_{2}$ management. IPCC also took cognisance of land use, soil management, and forestry as effective means for global carbon emissions. Brown et al. ${ }^{8}$ documented that global forestation programs 345 million ha of plantation and agro forestry would account to $60-87 \mathrm{Gtc}$ equivalent to $12-15$ percent of cumulated fossil fuel and deforestation emissions. Generally, it is accepted that trees do sequester carbon. Forestry poses a strong potential as a means of mitigating measure of greenhouse effect. Climate change, fire and forest owners also constitute a burden to forest sequestration capacity of $\mathrm{CO}_{2}$. Salient factors from carbon sequestration and forestry are as follows:

i. Forest as a potential carbon scrubber is considered to be cost effective

ii. Tropical forest may absorb more $\mathrm{CO}_{2}$

iii. Proper land and forest management supports larger terrestrial $\mathrm{CO}_{2}$ sink thereby supports afforestation

iv. Fast growing vegetation species and fertile lands are major benefits for $\mathrm{CO}_{2}$.

v. Generally, forestry in relative terms abates climate change, gas emissions and absorbs larger chunk of $\mathrm{CO}_{2}$.

\section{Recommendation}

This review paper provides an appropriate platform for the development of field based research project thereby a major support to knowledge and scientific understanding of $\mathrm{CO}_{2}$ sequestration.

\section{Conflict of interest}

Author declares there is no conflict of interest.

\section{Disclaimer}

This Mini-Review attracted some calculation methodology in which practitioners have identified the complexity of accounting and calculating the carbon sequestration by trees in an annual rate rather this has provided some useful insight of understanding that trees do sequester carbon. The author acknowledges all authors, websites and institutions that provided these basic calculation and information meant for more contribution to knowledge especially in this era of global change ecology.

\section{References}

1. http://www.rcfa-cfan.org/english/issues.13.html

2. Clark A, Saucier JR, McNab WH. Total-Tree Weight, Stem Weight, and Volume Tables for Hardwood Species in the Southeast. USA: Georgia Forestry Commission; 1986. p. 1-52.

3. De Wald S, Josiah S, Erdkamp B. Heating With Wood: Producing, Harvesting and Processing Firewood. USA: University of NebraskaLincoln Extension, Institute of Agriculture and Natural Resources; 2005.

4. http://www.worldagroforestrycentre.org/Sites/TreeDBS/aft.asp

5. Birdsey RA. Carbon Storage and Accumulation in United States Forest Ecosystems. USA: General Technical Report (GTR); 1992.

6. Sampson N, Hair D. Forests and Global Change: Forest management opportunities for mitigating carbon emissions. USA: American Forests; 1996

7. Myers N, Goreau TJ. Tropical Forests and the Greenhouse Effect: A Management Response. Jamaica: University of the West Indies; 1991.

8. Brown S, Sathaye J, Cannell MGR. Management of forest for mitigation of greenhouse gas emissions. In climate change 1995 Impacts, Adaptation and mitigation of climate change. In: Watson RT, et al. editors. UK: Cambridge University Press; 1996. p. 773-797. 